Fecha de recepción: febrero 2010 Fecha de aceptación: agosto 2010 Versión final: marzo 2011

\section{Los públicos de las comunicaciones financieras. Investor relations \& financial communications}

Daniel Néstor Yasky ${ }^{(*)}$

\begin{abstract}
Resumen: En los últimos años, se ha destacado la función de las comunicaciones financieras dentro de las Relaciones Públicas. Los requisitos de un mayor acceso a la información, transparencia y gobierno corporativo crean hoy desafíos significativos para todas aquellas compañías que cotizan en Bolsa, así como de firmas sin cotización oficial. El arte de comunicar en estas esferas, requiere la especialización de los profesionales para alcanzar el público adecuado con el uso de las herramientas pertinentes en el momento oportuno, transmitiendo el mensaje a la comunidad en forma estratégica. Para esto, hay que reconocer los actores destacados de este ámbito -como mercados de valores, agentes financieros internacionales, analistas, medios de comunicación, bancos, instituciones estatales, el parlamento, los empleados- y el intercambio que se produce entre la empresa y sus inversionistas.
\end{abstract}

Palabras claves: Comunicación Corporativa - Comunicación Empresaria - Comunicación Financiera - Comunicación Institucional - comunicadores - comunidad financiera - Dircom medios de comunicación - mercado de valores - público externo - público financiero - público interno - Relaciones con los Inversores - Relaciones Financieras - Relaciones Públicas - Reputación Corporativa.

[Resúmenes en inglés y portugués y currículum en la página 83]

En los últimos años, se ha destacado la función de las comunicaciones financieras dentro de las Relaciones Públicas, y también en el mercado financiero. En este proceso de aprendizaje, es importante identificar a las personas o instituciones que se involucran en la actividad. De hecho, son quienes están afectados e implicados en la vida empresaria cotidiana.

Los actores destacados en este ámbito, son informantes claves que participan activamente en el intercambio que se produce entre la empresa y sus inversionistas. Sin embargo, la comunidad va más allá de las partes mencionadas, incluyendo: mercados de valores, agentes financieros internacionales, analistas, medios de comunicación, bancos, instituciones estatales, el parlamento y los empleados.

La intención de reconocer a los actores, es comprender las dimensiones de comunicación a explorar, con el fin de satisfacer la cobertura informativa y construir un plan integrado, eficaz. El arte de comunicar en estas esferas, requiere la especialización de los profesionales para alcanzar al público adecuado. El uso de las herramientas pertinentes, en el momento oportuno debe dar sentido al comunicador para dar el mensaje a la comunidad en forma estratégica. La valiosa comunidad, demandante de información veraz, debe ser respetada. Por eso, el profesional siempre deberá 
actuar de manera activa, no meramente reactiva, explorando nuevas formas de llegar a ella. El punto es, ¿cuál es la comunidad financiera? ¿Existen otras maneras de denominarla? Thomas Rian, y Chad Jacobs (2005) hablan del 'mercado de capitales y sus jugadores', al referirse a ella expresan que:

Ninguna compañía pública funciona en un vacío. De hecho, mucha gente, incluyendo reguladores y competidores, generan opiniones que pueden afectar la posición de una compañía en los mercados de capitales. Cada decisión que una compañía toma, es financiera, estratégica, u operacional, la ondulación en los mercados de capitales y afecta el precio, el valor, la competitividad, o la opinión del público (Using investor relation to maximize equito valuation, $2005 \mathrm{pp} 23$ ).

Los autores lo grafican de la siguiente manera:

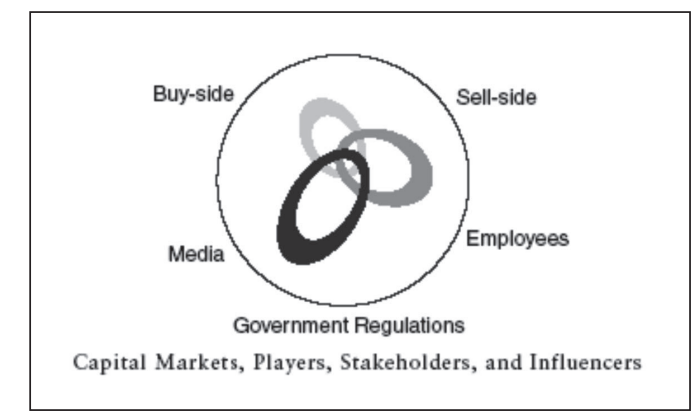

Figura 1: Jugadores e influenciadores en las relaciones financieras.

Fuente: Ryan, T. y Jacobs, C. (2005). Using investor relations to maximize equity valuation. New Jersey: John Wiley \& Sons.

Se observa a través de la interrelación que sugiere el gráfico que antecede, no sólo que quienes compran, venden acciones y sus intermediarios son parte del mercado. Sino, diversos grupos de interés (que también se pueden denominar intermediarios) dentro de los cuales se pueden incluir los empleados de una empresa, incluso los medios de comunicación.

Asimismo, Philip Lesly (1998) defiende la postura de los doce públicos financieros. Los grupos de influencia de los cuales habla son: sociedades de valores, agentes de cambio, miembros de sociedades de análisis de valores (y análisis independientes), bancos de inversión, comerciales, servicios de asesoría de inversiones, compañías de seguro y cajas de inversiones, consejeros de inversión, fideicomisarios de los estados e instituciones, organizaciones de estadísticas financieras, revistas de inversión y publicaciones financieras, compañías de fondos comunes de inversión. Por su parte, Grunig y Hunt (2003) describen los cuatro grupos de públicos financieros:

Accionistas actuales, accionistas anticipados, la comunidad financiera: banqueros, corredores, consejeros de inversión, administradores, analistas, y encargados de fondos mutuos, compañías de seguros, fondos de jubilación y medios financieros: periodistas que trabajan en 
medios especializados tales como el Wall Street, secciones de diarios financieros (Pág. 513).

La mirada de los autores, incluye a los banqueros en unos de los grupos que clasifican. La comunidad financiera propiamente dicha se enfoca en quienes son participantes activos. Además, los potenciales que podrían ser parte de esta comunidad.

Los empleados y funcionarios del gobierno son los jugadores involucrados por la dupla Ryan - Chads. En cambio, Grunig - Hunt, desarrollan la comunidad financiera propiamente dicha y los potenciales que podrían llegar a formar parte de ella. Lesly postulaba doce públicos financieros bien definidos precedentemente.

Los requisitos constantes del desarrollo de un mayor acceso a la información, de transparencia y gobierno corporativo crean hoy desafíos significativos para todas aquellas compañías que cotizan en Bolsa y de firmas sin cotización oficial. Los encargados de llevar a cabo las relaciones con los inversores de una empresa, tienen un papel vital en el desarrollo de la misma. Principalmente su función radica en comunicarse con mayor eficacia con la comunidad inversora; las Relaciones Públicas financieras son estrictamente una función de Relaciones Públicas de la empresa.

Sin embargo, Dennis Wilcox (2006) al respecto, desarrolla que quienes llevan a cabo las relaciones con los inversores 'son especialistas en la materia. En las grandes compañías pueden funcionar como una unidad independiente, y en las empresas más pequeñas pueden formar parte del departamento de relaciones públicas' (Pág. 334).

Según el Canadian Investor Relations Institute, la función de los relacionistas con los inversores (IROs) es "representar a todas las compañías que obran recíprocamente con la comunidad inversora. IROs también son empleados por las agencias de relaciones públicas como consultores para sus clientes corporativos" (Relaciones Públicas Financieras, 2008).

La National Investor Relations Institute define la actividad como 'una responsabilidad estratégica del management, utilizando disciplinas tales como las finanzas, la comunicación y el marketing, para administrar el contenido y el flujo de información financiera de una compañía para maximizar así el valor relativo de ésta' (Relaciones Públicas Financieras, 2008).

Es de vital importancia la labor de dicha práctica ya que si se proporciona información certera y confiable, esto conlleva a una toma de decisiones correctas. En esta línea, Judy Turk, Doug Newsom y Dean Kruckeberg (1999), expresan que las Relaciones Públicas Financieras o Relaciones con los inversores,

Es el área que incluye actividades semejantes como preparar el material para el estudio de la seguridad del accionista, desarrollar una memoria anual aceptable para los auditores y clara para los accionistas, y sabiendo dónde y a quiénes publicar las noticias que pueden afectar los valores de la compañía (Pág. 15).

Para la Investor Relations Society 'Las relaciones con los inversores abarcan la amplia gama de las actividades con las cuales una compañía cotizada se comunica con sus inversionistas actuales y potenciales' (Relaciones Públicas Financieras, 2008).

$P R$ Newswire coincide con esta postura al indicar que las relaciones con los inversores son 'esfuerzos emprendidos por las compañías para comunicarse con sus accionistas y analistas, y para brindar conocimiento de la compañía en la comunidad de la inversión general' (Relaciones Públicas Financieras, 2008). 
Sin embargo, otros autores como Bruce Marcus y Sherwood Wallace Lee plantean un objetivo más directo respecto a la función del relacionista público con inversores en cuanto a su relación con la comunidad financiera: 'persuadir a los inversores y analistas que el dólar invertido en su compañía se verá más incrementado en su valor que si, sustancialmente, ese dólar se invertía en otra compañía' (Relaciones Públicas Financieras, 2008).

El Institute for Public Relations, plantea que las relaciones con los inversores presentan dos dimensiones:

1. El Acuerdo: Securities and Exchange Commission (SEC), que regula a compañías públicas en los Estados Unidos. El deber principal del SEC es asegurar mercados justos y ordenados. Con este fin, ha promulgado las reglas y las regulaciones a las cuales las compañías públicas deben conformarse.

2. La Comercialización: una meta dominante de cualquier ejecutivo de las relaciones con los inversores es asegurarse que la acción de la compañía se está vendiendo en un valor justo. Hay también historias que demuestran que los ejecutivos de las relaciones con los inversores pueden aumentar la valuación de una acción usando principios simples de la comercialización. Apuntando a los inversionistas adecuados, formando un mensaje que será atractivo a estos inversionistas y a usar los canales de comunicaciones más eficientes (Yasky, 2010).

Estas dimensiones, refuerzan el concepto de transparencia y cumplimiento de regulaciones que toda comunicación financiera debe tener, en otras palabras, las prácticas de Buen Gobierno Corporativo.

Cuáles son algunas de las instituciones involucradas en el sistema de las relaciones públicas financieras (Investor relations):

\section{Sistema bancario}

Dentro de la comunidad financiera, los bancos tienen un rol protagónico en el ejercicio de la economía global. A través de ellos se canalizan las operaciones de pagos, transferencias de fondos, etc., es decir, actúan como intermediarios que no pueden faltar en la sociedad. Se observa que los bancos comerciales en general todos ofrecen los mismos servicios y productos.

John Marston, reconocido relacionista público, distingue en su clasificación las relaciones públicas de los bancos.

A su vez, el autor expresa la problemática que existe cuando hay manejo de fondos en grandes cantidades, para muchos el dinero es una influencia extraña y corrupta, aceptable en pequeñas cantidades. Otro problema, tiene su origen en las relaciones que este público tiene con el gobierno. 'El lugar de las negociaciones es más importante para la imagen de un banco que para otras instituciones' (Marston, 1990, pág. 63).

Si se relaciona que la crisis del 2001 produjo un escándalo a nivel imagen, difícil de ponderar. Aún hoy, las secuelas se evidencian, la conmoción fue tanto a nivel de los bancos hacia su público externo, y también, a nivel interno. ¿Cómo cambiar las actitudes luego de la pérdida de confianza? Más que palabras, los hechos pueden revolucionar. Al día de hoy, la recuperación es evidente. ¿De qué manera podemos cambiar? ¿Cómo evitar estos malos momentos en forma anticipada para las generaciones que vienen? 
El sector bancario se trata de una institución de innegable influencia en la vida económica de las naciones, es un intermediario estratégico.

\section{Sistema del mercado de valores}

El Mercado de Valores en nuestro país,

Es una entidad autorregulada, fundada en 1929. Su capital está integrado por acciones; sus tenedores (personas físicas o jurídicas) una vez que reúnen determinados requisitos, están habilitados para desempeñarse en carácter de Agentes o Sociedades de Bolsa, a fin de realizar transacciones de compra y venta de títulos valores por cuenta propia o de terceros. Las principales funciones del Merval están relacionadas con la concertación, liquidación, vigilancia y garantía de las operaciones realizadas en el mercado. (Locante, 2004, s/p).

En lo referente a la confianza de los consumidores 'Los consumidores se dividen en dos: los que no les alcanza el dinero para cubrir las necesidades básicas, y quienes perciben ahorros de sus ingresos'.

Otra institución relacionada, que se creó a partir de la Ley de Oferta Pública, es la Comisión Nacional de Valores, "una entidad autárquica con jurisdicción en toda la República. Su objetivo es otorgar la oferta pública velando por la transparencia de los mercados de valores y la correcta formación de precios en los mismos, así como la protección de los inversores" (¿Qué es la CNV?, s/f) en www.cnv.gov.ar).

En 1968 inició sus actividades, cuya misión es regular, fiscalizar y controlar a los participantes del mercado de capitales, vigilando que sus operaciones cumplan con los principios y objetivos (en conformidad con la Ley de Oferta Pública de Títulos Valores, de Fondos Comunes de Inversión y de Fideicomisos Financieros y del Decreto de Calificadoras de Riesgo).

El público inversor, ¿ conoce que el Mercado de Valores ofrece productos y servicios que pueden satisfacer sus necesidades financieras? Las Pymes, ¿ conocen los beneficios que poseen al invertir en acciones?

\section{Sistema de la bolsa de comercio}

La Bolsa de comercio es

una institución independiente que cumple la función de nexo entre las empresas y los inversores. Aquellas empresas que desean abrir su capital a oferta pública, se acercan a esta institución y luego de cumplimentar los requisitos necesarios para abrir su capital al público en general, están en condiciones de entregar parte de su capital accionario a cambio de dinero. (El accionista, julio 2006).

Estas entidades tienen lugar en todo el mundo, con similares funciones.

La Bolsa de Comercio de Buenos Aires (BCBA),

Fue fundada en el año 1854, como un centro de negocios y de comercialización de productos, acciones y bonos. Actualmente es una asociación civil autorregulada, sin fines de lucro. $\mathrm{Su}$ Consejo es integrado por representantes de diferentes sectores de la economía. Está 
legalmente autorizada para admitir, suspender y cancelar la cotización de títulos valores, de acuerdo con sus propios reglamentos, aprobados por la Comisión Nacional de Valores. (Bolsa de comercio de la ciudad de Buenos Aires, 2006)

Según Lesly (1998), "las Bolsas de Valores requieren que la información que pueda afectar materialmente el mercado de valores de una compañía sea prontamente revelada. Deberían aplicarse reglamentaciones parecidas para los valores que no están en la Bolsa” (pág.67).

Así, el autor brinda una serie de orientaciones sobre la política de revelaciones de la Bolsa.

Para Philip Lesly (1998) es importante respetar los siguientes principios:

- Revelación pública inmediata de la información pertinente

- Difusión pública completa

- Aclaración o confirmación de rumores e informes

- Respuesta a la actividad inusual del mercado

- Revelaciones promocionales injustificadas

- Transacciones del personal interno de la compañía

Para la problemática financiera, se consideran principios básicos, inclusive en el desarrollo de un país, es posible aplicar estos principios. Los cuales favorecen a la transparencia de la organización, sea cual fuere su misión. En cuanto al contenido del anuncio es tan importante como la medida del tiempo en que se entregará. Al mismo tiempo, deberán ser claros, ciertos y sucintos, con información cuantitativa para que los inversores puedan evaluar su importancia relativa, equilibrados y razonables, con lenguaje súper tecnificado, explicar consecuencias o efectos de la comunicación.

\section{¿Cómo se opera en la Bolsa?}

- La Rueda, que en realidad es el modo tradicional, que casi no se utiliza.

- SINAC (Sistema Integrado de Negociación Asistida por Computador). El más utilizado. Este sistema permite ingresar las operaciones al conmutador central.

- Negociación recurrente: Los operadores pueden ingresar en el SINAC las ofertas de compra o venta desde sus oficinas o en el recinto mismo a través de las terminales allí instaladas, computadoras de mano, o solicitando a los empleados de la BCBA que las ingresen.

\section{¿Qué se negocia en la Bolsa?}

Acciones: Representan los aportes de capital de los accionistas.

Aunque la mayoría de las firmas tienen solamente un tipo de acción ordinaria, a veces la acción clasificada se utiliza para resolver las necesidades especiales de la compañía. Generalmente, cuando se dan situaciones especiales, se señala una clase A, otra clase B, y así sucesivamente (Bowker corporate finance book - Estados unidos - 1995-p.185).

Obligaciones negociables (ON): La ley 23576 (Ref: Anexo) "Las sociedades por acciones, las cooperativas y las asociaciones civiles constituidas en el país, y las sucursales de las sociedades por acciones constituidas en el extranjero pueden contraer empréstitos mediante la emisión 
de obligaciones negociables". Representan unidades de un empréstito a mediano o largo plazo contraído por la sociedad para el desarrollo de sus proyectos de inversión u otros fines. La emisora paga a los obligacionistas, que son sus acreedores, el interés estipulado y cancela las obligaciones en la forma y plazo acordados.

Obligaciones negociables convertibles: 'Obligaciones negociables que pueden ser convertidas en acciones de la sociedad emisora a voluntad del titular y de acuerdo a las condiciones estipuladas al emitirlas'. (Bull market brokers, s/f)

Obligaciones negociables PyMES: Emitidas por pequeñas y medianas empresas, bajo un régimen simplificado de oferta pública y cotización en la BCBA.

Valores fiduciarios: Son certificados de participación o valores representativos de deuda que se emiten en fideicomisos financieros, en los cuales el fiduciario ejerce la propiedad de los bienes en beneficio de los titulares de esos valores a cuya garantía quedan afectados.

CEDEARs: Tal como lo define la Bolsa de Comercio, son certificados representativos de depósito de acciones de sociedades extranjeras u otros valores, sin autorización de oferta pública en nuestro país. Quedan en custodia en la Caja de Valores y se pueden negociar como cualquier acción.

Bonos Públicos: Son empréstitos emitidos por el Estado Nacional, Provincias o Municipalidades. Los inversores perciben la renta estipulada y la devolución del capital en la forma y plazo acordados.

Fondos comunes de inversión cerrados:

Es un patrimonio (dividido en porciones llamadas cuota partes), conformado cuando un grupo de personas con los mismos objetivos de inversión (o sea que esperan la misma rentabilidad y están dispuestos a asumir el mismo riesgo), reúne tu dinero para que sea administrado por un equipo de profesionales. Estos profesionales llevan a cabo las políticas de inversión establecidas en el Reglamento de Gestión (INTA, s/f)).

Cheques de pago diferido: La CNV ha autorizado la negociación con cheques de pago Diferido (emitidos por 30 hasta 360 días vista). La reglamentación de la Bolsa prevé la negociación de cheques patrocinados (cuando la solicitud incumbe a la libradora) y los avalados (por una sociedad de garantía recíproca o una entidad financiera).

\section{Organismos Internacionales de Crédito}

\section{¿Qué es el FMI (Fondo Monetario Internacional)?}

"Es una organización integrada por 184 países, que trabaja para promover la cooperación monetaria mundial, asegurar la estabilidad financiera, facilitar el comercio internacional, promover un alto nivel de empleo y crecimiento económico sustentable y reducir la pobreza" (Clift, 2004, pág. 6). 
La institución central del sistema monetario internacional, creada en 1945, permite la actividad económica entre los países del mundo. Tiene como objetivo principal: evitar crisis, y provee financiamiento a los países que padecen problemas en sus balanzas de pago.

Entre los fines se pueden mencionar los siguientes:

- Efectúa el seguimiento de la evolución y las medidas de política económica y financiera, en los países miembros y en el mundo, y ofrece asesoramiento de política a los países miembros. - Concede préstamos a los países miembros que enfrentan problemas de balanza de pagos.

- Facilita a los gobiernos y bancos centrales de los países miembros asistencia técnica, capacitación en el área de especialidad de la institución.

El FMI se centra principalmente en la política macroeconómica, medidas de política que tienen que ver con el presupuesto público, la gestión de las tasas de interés, el dinero y el crédito, y el tipo de cambio y la política del sector financiero, que comprende la regulación y supervisión bancarias y de otras entidades financieras. Por este motivo, es importante conocer a este organismo.

\section{¿Qué es el Banco Mundial?}

El Banco Mundial es una fuente vital de asistencia financiera técnica para los países en desarrollo de todo el mundo. No somos un banco en el sentido corriente. Esta organización internacional es propiedad de 184 países miembros y está formada por dos instituciones de desarrollo singulares: el Banco Internacional de Reconstrucción y Fomento (BIRF) y la Asociación Internacional de Fomento (AIF) (Grupo del Banco Mundial, s/f)

Las instituciones tienen finalidades diferentes, más el objetivo común es reducir la pobreza en el mundo, aumentando los niveles de vida de la población. La primera, se enfoca en países de ingreso mediano y pobres con capacidad crediticia. La segunda, ayuda a los más pobres del mundo. Ambas, ofrecen préstamos a los intereses más bajos, cuyo destino puede ser: educación, salud, infraestructura, comunicaciones, entre otros.

Además, el Banco Mundial posee instituciones afiliadas, entre las cuales se destacan:

- Corporación Financiera Internacional (CFI): es una institución afiliada del Grupo del Banco Mundial que se ocupa del sector privado. Y, cuya misión es fomentar la inversión sostenible del sector privado en los países en desarrollo, para así ayudar a reducir la pobreza y mejorar la calidad de vida de la población.

- Organismo Multilateral de Garantía de Inversiones (OMGI): la misión es promover la inversión directa extranjera (FDI) en países en vías de desarrollo, la ayuda al desarrollo económico, con el fin de reducir pobreza, y mejorar las vidas de la gente.

- Centro Internacional de Arreglo de Diferencias Relativas a Inversiones (CIADI) Se diseñó especialmente facilitar el establecimiento de los conflictos de la inversión entre los gobiernos y los inversionistas extranjeros, y además, podría ayudar a promover flujos crecientes de la inversión internacional.

Por su parte, "Los bancos multilaterales de desarrollo son instituciones que proporcionan apoyo financiero y asesoramiento profesional para actividades orientadas al progreso económico y social en los países en desarrollo" (Grupo del Banco Mundial, s/f). 


\section{Estrategias de Relaciones con los inversores}

Las empresas deben diseñar una estrategia a seguir para que su relación con el público financiero sea eficaz y así focalizar sus acciones comunicativas con éxito y favorecer el acceso a la información de todos los públicos que intervienen en el proceso.

$\mathrm{Al}$ respecto, Marcus y Wallance Lee proponen un mecanismo para desarrollar una estrategia con el público inversor:

-Definir el objetivo.

-Definir la posición (el mensaje clave que será enviado).

-Seleccionar la audiencia (grupos de analistas, brokers49, inversores individuales) y las personas clave de cada grupo.

-Determinar cómo el mensaje va a ser enviado.

-Preparar los materiales apropiados (presentaciones, documentos).

-Organizar reuniones.

-Seguimiento (1998, pág. 102).

Sin embargo, no todas las empresas son iguales como así tampoco lo es su capital, en el caso de empresas más pequeñas, Roger S. Pondel, en un documento de Investor Relations revela seis importantes estrategias para relacionarse con los inversionistas:

Primero: concentrarse en la economía real; no esté asustado de decir a sus accionistas que incluso si no hay beneficios todavía, la compañía esté en el negocio para hacer el dinero.

Segundo: ser amigo de los analistas que siguen tus competidores, y si usted no tiene competidores, identifique a analistas que siguen sus pares más cercanos.

Tercero: haga lo mismo con los encargados de manejar el portafolio que posean sus competidores y pares.

Cuarto: manténganse al frente en los medios, los medios del negocio tienen hambre de contenido.

Quinto: utilice su página en internet.

Sexto: maximice el valor que sus clientes y vendedores ponen en su compañía haciéndola atractiva y fácil para que se sientan bien sus accionistas (s/f).

El Institute for Public Relations, plantea que hay dos estrategias distintas, una para con los inversores institucionales y, la otra, para con los inversores individuales.

Con respecto a las primeras, establece que lo fundamental en la estrategia con los inversores es comunicarse con los analistas. Es un proceso directo. Los analistas de firmas importantes cubren a industrias y a compañías específicas. Es fácil identificar qué analistas siguen su industria y, por lo tanto, deben seguir su compañía. Por último ellos les llevan la información a sus clientes. El segundo paso en las relaciones con los inversores, es asegurarse de que estén cubriendo a su compañía en los principales servicios de consultoría (s/f).

Con respecto a los inversores individuales, el escrito afirma que son pocas las compañías que tienen estrategias para con ellos, sin embargo, los inversores individuales son atractivos para algunas compañías porque tienden a comprar la acción y sostenerla. Para alcanzar a estos inversores, propone: llegar a los analistas y asegurarse que la compañía esté cubierta por los servicios 
de consultoría principales. Otras tácticas incluyen: mail a los corredores de las firmas donde los analistas han escrito informes positivos sobre la compañía, marketing en los centros de inversión y publicidad corporativa (Institute for Public Relations, s/f).

\section{Comunicaciones Financieras}

Las comunicaciones financieras son aquellas acciones de comunicación, cualquiera que sean las técnicas o herramientas empleadas, dirigidas y encaminadas desde entidades y empresas del sector público y del privado, con el objetivo de crear un nexo entre la empresa y la comunidad financiera. Esta comunidad financiera está determinada por los actores que se ven involucrados en las finanzas de la organización.

Como toda comunicación, necesita de diversas herramientas para transmitir sus mensajes; en el caso particular de las financieras, podemos afirmar que hay una herramienta por excelencia e ineludible a la vez, ya que actualmente se cuenta con regulaciones que establecen su contenido garantizando el acceso a la información de la situación económica y financiera de las corporaciones. Estados Unidos cuenta con la Securities and Exchange Commission (SEC), "una agencia federal que regula los mercados financieros de ESTADOS UNIDOS. Esta agencia federal también supervisa la industria de seguridades y promueve el acceso y la protección completos del público de inversión contra la negligencia en los mercados". (Forbes financial glossary, 2005)

Fleishman-Hillard (2005) añade que las comunicaciones financieras "identifican y atraen a los inversores y crean la credibilidad y, junto a ella, el valor futuro de la organización”. (s/p)

Por su parte, y en el mismo sentido, Burson Marsteller (2005) expresa que "Las comunicaciones financieras pueden conducir al crecimiento de una compañía, de hecho son tan importantes que deben ser manejadas estratégicamente como las finanzas, administración, tecnología, etc.” (s/p). Además de la memoria o reporte anual, las comunicaciones financieras cuentan con otras herramientas, sin embargo el reporte anual y el $10 \mathrm{~K}$ son dos documentos que el área de Relaciones Públicas o las empresas deben preparar. El reporte anual hace que las herramientas promocionales sean utilizadas por los corredores y la compañía misma en presentaciones para todos sus miembros del público financiero, desde bancos hasta analistas. Cuando el reporte anual es distribuido, un nuevo informe resume los puntos principales y anuncia la publicación del reporte. Los esfuerzos de hacer del reporte anual un documento integrado no estuvieron bien, entonces la SEC utiliza el 10K como la más importante forma de integrar los mensajes de la gerencia con los reportes financieros (Newson,Turk y Kruckeberg, 2006, pág. 263).

Seguidamente, se analizarán las herramientas que habitualmente se utilizan para llevar a cabo la comunicación financiera.

\section{Herramientas de las comunicaciones financieras}

Se trata de instrumentos que poseen las empresas para definitivamente transmitir el mensaje a la comunidad financiera. "Las técnicas de comunicación, son más que un ejercicio tradicional de práctica de relaciones con los inversores". (Marcus / Pág. 101) Según Marcus (1998), para persuadir a inversores y a analistas que un dólar invertido en la propia compañía aumentará de valor más rápidamente y más substancialmente que un dólar invertido en otra compañía se debe incrementar la persuasión.

Ante las objeciones presentadas por inversores, los especialistas deben tener un amplio conocimiento del mercado, un análisis comparativo de los beneficios que reportan, la valoración de 
sus ventajas, y recursos competitivos que posee.

Como se ha mencionado en la evolución histórica de las relaciones con inversores, la Securities and Exchange Comnission (SEC) exige a las compañías que entreguen informes a sus accionistas. En cuanto a las herramientas mínimas obligatorias, ¿qué se requiere?

"La SEC incluye más información en las memorias anuales: datos financieros que datan de hasta cinco años atrás y un amplio comentario y análisis de la condición financiera, así como los resultados de explotación”. (Grunig-Hunt, 2003, pág. 717)

Las habilidades profesionales, el diseño y redacción del contenido de las distintas comunicaciones, son elementales para garantizar la efectividad de las comunicaciones financieras. ¿Qué herramientas se han utilizado para llegar a los consumidores bancarios? ¿Cuáles han sido más efectivas para lograr la confianza? Se intentan observar la estrategia en su máxima expresión para arribar a la conclusión de la investigación.

Algunas características de las principales herramientas:

\section{Memoria y balance}

Es un instrumento que representa los resultados financieros de una empresa. Los cuales expresan la realidad material, el funcionamiento y las aspiraciones de la organización. Se trata de información pública y obligatoria, que se manifiesta hacia los diferentes stakeholders para formar una opinión favorable. Philip Lesly afirma:

Un punto clave de la memoria anual es el retrato del carácter y perspectivas de la dirección de la compañía. Las compañías que gastan millones de dólares en sistemas de identidad visual, publicidad corporativa, y otros programas orientados a presentar la compañía como una empresa cálida, progresiva y orientada hacia el público, a menudo miran los esfuerzos del informe anual (1998, pág. 199).

Para cumplir con su propósito, las memorias y balances deben incluir

ventas realizadas normalmente, estado financiero, nuevos productos y sus posibilidades, inversiones probables y el uso que se proyecta darles, planes de modernización de plantas y negociaciones en curso con autoridades públicas, problemas actuales y proyectos para resolverlos, y perspectivas del mercado (Fernández Escalante, 1999, pág. 125)

Desde el punto de vista del inversor facilita la comprensión y refleja la solvencia de la empresa, hechos que generan valor en el momento de decidir en qué empresa invertir. También, permite la evolución por parte de la comunidad financiera, ¿se cumplieron los resultados proyectados? ¿De qué manera responde la empresa a los problemas?

Por su parte, Cutlip (2001) simboliza a la herramienta de uso externo como una piedra angular de cualquier programa de relaciones públicas financieras. "Esta herramienta ha alcanzado gran sofisticación desde el punto de vista técnico y gráfico, debido, en parte, a sus objetivos de relaciones públicas dirigidos a los diferentes públicos" (pág 567). No obstante, el autor postula que como consecuencia de los tiempos económicos difíciles, es necesario reconsiderar los gastos relacionados con la producción del instrumento.

Un informe fiscal dirigido a los inversionistas al finalizar el año incluye: "comunicación del 
CEO y un resumen básico del negocio, incluyendo el texto en operaciones, las tablas de la auditoria financiera revisados con el sistema GAAP (Generally Accepted Accounting Principales) constituidos por declaración de renta, flujos de liquidez, balances, y las notas que explican las asunciones detrás de esos números.

Éste es fácil de entender, diseñado gráficamente, es una variante del 10-K” (Ryan y Jacobs, 2005, pág 78) resaltan la relevancia del reporte, al atribuir al management de la organización su elaboración. Por supuesto, la creación del elemento estará orientada por un profesional de Relaciones Públicas.

"Técnicamente, la memoria anual de una empresa es un documento informativo que la Comisión del Mercado de Valores exige a todas las empresas para fines de relaciones públicas. Estos incluyen:

1. Recalcar a accionistas presentes y potenciales el hecho de que la empresa está bien gestionada y tiene éxito.

2. Fomentar compras de acciones por inversores potenciales, y

3. Usar la memoria anual como instrumentos para incorporar nuevos empleados". (Wilcox, pág 563).

\section{Asamblea Anual}

Es un encuentro de accionistas, que favorece la interacción entre el público específico y el directorio de la compañía.

Se trata de un procedimiento exigido y regulado por la SEC que simboliza la democracia corporativa en la práctica y proporciona la oportunidad de contactos personales, solamente de personas que se encuentren en el mismo ámbito geográfico o que controlen un gran número de acciones pueden dedicar el tiempo y gastos necesarios para asistir. (Cutlip, pág. 569)

Los citados autores responsabilizan a los profesionales de relaciones públicas para la Organización de el encuentro, quienes se encargan de: los preparativos, folletos y materiales de comunicación, convocatoria de los medios de comunicación (cobertura mediática), Q \& A (questions and answer). Estos últimos son las posibles preguntas que los accionistas pueden presentar a los directivos de la empresa y las posibles respuestas a dichos cuestionamientos.

Coincidentemente, Ryan enseña un concepto similar al de Cutlip, dice que "la compañía encuentra una vez al año con todos los shareholders invitados. Algunas compañías tienen distintas distribuciones geográficas y números de shareholders. El manager y directores presentan discusiones sobre problemas y decisiones" (Ryan-Jacobs, 2005, pág 62).

Dicho de otro modo, los directivos rinden cuentas a sus públicos sobre las acciones financieras, sobre la rentabilidad obtenida y también las proyecciones futuras.

Para Seitel (2002), un encuentro anual "bien pensado, planificado y bien ejecutado, puede permitir a encargados corporativos comunicarse con eficacia con los inversionistas" (pág 407). El especialista agrega elementos de planificación estratégica de relaciones públicas para enfatizar en los resultados positivos que se pueden adquirir, siempre actuando en forma proactiva. Se entiende que toda comunicación implica acción, por tanto, teniendo en cuenta el impacto que puede provocar, es importante detectar la necesidad de comunicación: el objetivo. 


\section{Folletos y Publicaciones}

El diseño, estilo, el contenido y la creatividad son condiciones estratégicas para la comunicación a través de estas herramientas. Pueden adoptar formato en escrito o electrónico.

Teniendo en cuenta la saturación informativa producida en el último tiempo, es tarea del comunicador transmitir el mensaje de modo que trascienda los parámetros normales.

Dennis Wilcox (2006) presenta consideraciones para la creación de un boletín informativo, describe la importancia que radica en este tipo de medio por su capacidad comunicativa y retención del mensaje. Agrega que, los boletines se dirigen a los públicos activos y pasivos, de este modo la publicación puede llegar a la extensa comunidad financiera.

El citado autor ha expresado que tanto los boletines, como periódicos, revistas, folletos y manuales "son un elemento principal del modelo de información pública y es frecuente que compartan los defectos de este modelo. Los profesionales los publican sin investigar para descubrir si hay un público que necesita la información o la encuentra relevante" (Wilcox, 2006, p. 568). La aclaración del autor, permite a los profesionales evaluar la necesidad de información, es decir, no se trata de realizar acciones comunicativas por el hecho de simplemente hacerlas. Sino, por el contrario, respetando los principios de relaciones públicas, se debe ponderar y establecer prioridades de comunicación y públicos a los cuales se dirigen, estableciendo precedencias.

\section{Publicidad Financiera}

Se trata de la aplicación de técnicas y estrategias de comunicación publicitarias dirigidas a un público específico "la comunidad financiera". La publicidad ha cambiado su original función de servir a la comercialización de un producto o servicio. Hoy, más bien intenta imponer a la sociedad un estilo de vida, a través de los hábitos que se proyectan en las imágenes.

"El dar a conocer; llamando la atención pública a un producto, a un servicio, o a una compañía por medio de avisos pagados para afectar la opinión o despertar el deseo del consumidor de hacer una compra o de tomar una acción particular" (Motto, 2006).

La finalidad propia de la publicidad al servicio del ámbito financiero, explica la importancia que tiene la herramienta para dar cobertura a la comunidad financiera. Este tipo de publicidad produce impacto, y aumenta el nivel de confianza en los consumidores. Si se hace un paralelo con la problemática que se estudia, este medio de comunicación es estratégico para aumentar el nivel de confianza de los consumidores.

"La publicidad no es la normalidad. Lo normal en publicidad no interesa, no impresiona". (portal de comunicación Sonia Rykiel, 2006)

¿Hasta qué punto es permisible la anormalidad para provocar, para establecer un lazo entre el cartel (anuncio) y el público?". Se entiende que desde que una idea nace, hasta que empieza a ser rentable existe un proceso de innovación. Ese proceso, se puede dividir en etapas:

Oportunidad, Territorio, Enfoque, Ideas y Soluciones, ha postulado Eduardo Kastica en su obra Desorganización creativa (2001).

Para organizar el trabajo, es necesario abordar la idea a través de pasos, lo cual no significa limitar sus efectos. Es importante saber, que la idea debe solucionar algo a alguien.

Hoy en día, se buscan formas originales de impactar en el público a través de la publicidad. Al acceder al subte, se puede observar una luz que proyecta la imagen de una marca en el suelo.

Las agencias, realizan estudios críticos de ubicación, tecnología a utilizar, para que el efecto sea múltiple. La imagen no está ubicada en cualquier parte de la estación. El lugar es estratégico. 
Los consumidores, en ese momento no pueden dejar de mirar hacia abajo porque están bajando las escaleras para acceder a la plataforma. Al finalizar el descenso, se encuentran con la famosa marca que lo acompaña todos los días a su casa o al trabajo.

Lesly explica, "la publicidad financiera alcanza al accionista actual y al futuro, al tiempo que proporciona mucha de la información que debe dirigirse a la comunidad financiera profesional”. (Lesly, 1998, pág. 215)

Luego, el autor menciona las áreas de interés de esta herramienta: la elaboración de notas de prensa, que incluyen contenidos de las memorias y asambleas, comunicados de prensa, los discursos sobre temas financieros de los funcionarios de la compañía ante grupos de negocios, entrevistas en publicaciones financieras y reuniones con los medios de comunicación. Además, Lesly puntualiza que se derivan muchas otras áreas en temas financieros, por ejemplo; nuevos productos, programas de becas, proyectos comunitarios, declaración de contribuciones de la compañía.

\section{Tele-conferencias}

Actualmente, son encuentros que pueden ser personales, por video, por Internet, cuya función es favorecer la interacción entre la compañía y la comunidad inversora. Dicho de otro modo,

"es una manera eficaz y más común para dibujar al inversor, analizar y centrar la atención en los accesos recientes de la compañía. La llamada en conferencia permite que los jugadores de los mercados de capitales escuchen el resumen de la gerencia mayor, los accesos recientes, y las actividades significativas, así como escuchar sus preguntas" (Ryan-Jacobs, 2005, p. 64).

La definición de la herramienta, supone la escucha activa por parte de los directivos de la compañía. Desde luego, se caracteriza por integrar diferentes regiones mundiales de la compañía y de la comunidad financiera.

Sin embargo, el sentido de oportunidad es el elemento esencial para la convocatoria. Cualquier motivo o circunstancia no es relevante. En el mundo de los negocios, el tiempo tiene un valor. Por tanto, discernir el momento adecuado y la razón es básico para el profesional de relaciones públicas que lleva a cabo la convocatoria.

Marcus distingue algunos principios que se pueden tener en cuenta para llamar a una nueva conferencia. Cuando:

una noticia es monumental, una razón clara, tal como una demostración de un producto nuevo o la necesidad de una explicación elaborada, porque las noticias no se pueden cubrir en un lanzamiento de los medios, la comprensión completa de las noticias requiere preguntar y elaborar las respuestas (1998, pág. 222).

La perspectiva del autor proporciona elementos cognoscitivos para evaluar la realización de una conferencia. Su aporte, desemboca en la noción de feedback, los Q \& A (questions and answers) involucran el ida y vuelta que sirve para aclarar temas de asuntos de interés.

\section{Newsletters}

Se trata de un tipo de publicación que llega a un público específico, selecto. 
Como pequeños cuadernillos de no más de 24 páginas, formato sencillo y de bajo costo de edición, las newsletters aparecieron en la década de los años ' 80 en nuestro país, llegando a los escritorios de líderes de opinión ávidos de encontrar informaciones que no pueden acceder en los medios de acceso público (Avilia Lammertyn, 1997, pág. 202).

Para Grunig \& Hunt, (2003) los programas de Relaciones Públicas internas incluyen la redacción del house organ. Luego, diferencian otros tipos de publicaciones de similares características. Estas son las revistas, los periódicos, los boletines internos y las revistas periódicos. La descripción que postula sobre los newsletter, son "más sencillos, más rápido y menos complicados que las demás publicaciones. Son lo suficientemente flexibles para satisfacer las necesidades de pequeñas organizaciones y pueden ser impresos". (Grunig, 2003, pág. 363). Hoy, las nuevas tecnologías permiten que esta herramienta adquiera diferentes formatos, incluso virtuales, cuyo costo es reducido.

Otros denominan la herramienta cartas a los accionistas y se entiende que el alcance de la palabra aquí se amplía. Lesly, dice que las dichas cartas "son uno de los medios más efectivos de cultivar el interés y la confianza de los nuevos accionistas. Es por medio de una carta de bienvenida del presidente de la compañía que se envía tan pronto como las acciones han sido registradas" (Lesly, 1998, pág.214).

Existen casos en los que la compañía luego de cambiar su nombre o identidad visual, decide comunicar a sus clientes a través de una carta de similares características. El objetivo en ambos casos es el mismo: establecer un vínculo continuo con accionistas o clientes también, ya que sin ellos las empresas no subsisten.

Tal vez, en el caso que se estudia, hubiese sido útil el newsletter o cartas a los inversores con el fin de aclarar la situación en forma personalizada. Los bancos, por diferentes razones políticas, económicas y sociales, optaron por el silencio que se prolongó por más de un año.

¿Cómo hubiese reaccionado la opinión pública si se hubiesen enviado newsletters con una invitación para visitar las instalaciones bancarias? ¿O cuál sería la opinión de los ahorristas, si se hubieran enviado cartas con contenido informativo sobre la evolución de los depósitos?

\section{Presentaciones y Road Shows}

La estructura de la presentación debe estar dirigida a lograr un compromiso en la acción. Toda presentación debe persuadir a los interlocutores a actuar en respuesta al mensaje emitido.

El moderador debe resaltar los puntos claves. Antes de finalizar la presentación debe repetirlos en forma ordenada, mencionar los beneficios para facilitar la retención de la audiencia.

Las presentaciones estarán dirigidas a la comunidad financiera, al público especializado, analistas financieros y líderes de opinión. Quienes deben recibir información completa y concisa sobre los temas financieros. Al mismo tiempo, existen ciertos requisitos que se deben cumplir para que el arte de presentar sea eficaz. Las condiciones se resumen en los siguientes términos: Brevedad, puntos claves, organización, despertar interés, substancial, conclusiones.

Geri Stengel (2006), ha estudiado los diferentes puntos antes mencionados. El especialista, aclaró que "proporcionar la sustancia es definir el mercado actual y el potencial: los inversionistas desean dar a conocer el mercado y el gran potencial que tiene el mercado. Describir el tamaño, características, potencial de crecimiento y tendencias" (s/p).

En gran medida, las variables mencionadas influirán en la decisión de compra de acciones. 
Paralelamente, la compresión que se logre por parte de los stakeholders hará que éstos se constituyan como transmisores de imagen de la compañía.

En tanto, Grunig hace referencia al término presentaciones multimedia. Se evoca de este modo, "la combinación de imágenes múltiples y diversos formatos audiovisuales puede ser una forma eficaz de atraer la atención, presentando un concepto complejo de múltiples facetas, y evocando fuertes respuestas emocionales". (2003, pág. 712). Estas presentaciones incluyen la televisión, diapositivas en la empresa entre otras.

\section{Internet}

Internet constituye el instrumento más nuevo para las comunicaciones con las audiencias inversoras, así como una fuente virtual de búsqueda de información. El mundo virtual ha provisto a las organizaciones de fluidez en el contacto, favoreciendo la publicación de la totalidad de cuestiones importantes que se relacionan con el desarrollo de la empresa. Así, las empresas pueden comunicar su identidad, su misión, valores, sus servicios y acciones. Internet, es conocida como una red de redes a nivel mundial a la que se encuentran interconectadas, por un mismo lenguaje, muchos usuarios. Indudablemente, las nuevas tecnologías trajeron aparejados nuevos cambios de hábitos en la manera de pensar, de actuar, de ponderar y aún de expresar. El mundo virtual ha provisto a las organizaciones de fluidez en el contacto, favoreciendo la publicación de la totalidad de cuestiones importantes que se relacionan con el desarrollo de la empresa. Así, las empresas pueden comunicar su identidad, su misión, valores, sus servicios y acciones. Internet, es conocida como una red de redes a nivel mundial a la que se encuentran interconectadas, por un mismo lenguaje, muchos usuarios. Indudablemente, las nuevas tecnologías trajeron aparejados nuevos cambios de hábitos en la manera de pensar, de actuar, de ponderar y aún de expresar.

En la problemática, es un factor clave, el conocimiento de la herramienta aplicada para favorecer el crecimiento de la bancarización en Argentina. De este modo, se está obedeciendo a la política pública implementada por el Gobierno para cumplir con las exigencias de las entidades financieras internacionales. Entonces, Internet ¿constituye un elemento de control internacional?

Se anticipa que no se trata de un enfoque semejante. El punto clave, es que Internet simplifica las transacciones bancarias pudiendo ser realizadas aún desde el propio hogar, sin apersonarse en un banco. Hay que recordar, que para gozar del servicio el ciudadano debe estar bancarizado. Es decir, como mínimo debe poseer una cuenta bancaria (caja de ahorro).

Trascendió que en los últimos años, los consumidores han incrementado sus operaciones a través de Internet. Incluso, se puede decir que ha favorecido el vínculo entre los bancos y los consumidores. Se trata de una cultura reciente, que implica conocimientos técnicos de informática por parte del usuario (consumidor, comunidad financiera) y deja de lado a quienes no tienen acceso a estos ámbitos.

Actualmente, los bancos en Argentina brindan servicios a través de Internet que permiten al público: consultar operaciones, movimientos, pagar servicios y tarjetas de crédito, comprar, transferir dinero a otras entidades y recientemente, hasta se puede invertir en plazo fijos electrónicos. Para el acceso a homebanking, se requiere la adhesión de una tarjeta de débito a una cuenta bancaria. En otras palabras, la tarjeta de débito habilita al cliente a operar a través de la banca electrónica en sus diferentes formas: por cajeros automáticos, banca telefónica y por Internet. Marcus afirma: 
En internet, hoy no hay virtualmente información o noticias corporativas que no estén disponibles. Las Webs de las compañías incluyen generalmente las noticias de la compañía, noticias de los accionistas, información de producto, noticias de la gerencia, y el espectro completo de la información de la compañía”. (1998, pág. 308).

Esta aseveración permite establecer las siguientes aclaraciones: por un lado, la página expresa la totalidad de la compañía y refleja sus componentes visuales. Por otra parte, se deduce que aquel dato no encontrado por el usuario le permite indagar a la empresa a través del sitio.

En cierta medida, se puede afirmar que la herramienta es un elemento de control, el cual sirve para corregir desvíos y para nutrir la relación entre las entidades y consumidores.

\section{Algunos casos importantes de fraudes financieros}

\section{Enron (2001)}

Séptima empresa de Estados Unidos, dedicada a la distribución de energía.

- En octubre del 2001, Enron declaró que había amortizado inversiones fallidas por importe de 1 mil millones de dólares y efectuó una reducción del capital social por importe de 1,2 mil millones de dólares. Las autoridades estadounidenses iniciaron una investigación sobre la empresa.

- En noviembre del 2001 Enron regularizó sus estados financieros correspondientes al período comprendido entre 1997 y 2001, para contabilizar casi 600 millones de dólares de pérdidas, que había ocultado en complejas operaciones financieras. Standard \& Poor’s rebajó la calificación de la deuda de Enron al nivel de los bonos basura.

- Enron instó la declaración judicial de quiebra en diciembre del 2001.

\section{WorldCom (2002)}

Empresa estadounidense de telecomunicaciones, principal proveedor mundial de servicios de internet y de comercio electrónico.

- En junio del 2002, WorldCom admitió que había manipulado considerablemente sus cuentas, principalmente declarando erróneamente costes como gastos de capital. Si se considera el período a partir del 2001, 3,8 mil millones de dólares de supuestos beneficios debían haberse declarado como pérdidas.

- WorldCom instó la declaración judicial de quiebra más importante de la historia de Estados Unidos, en julio del 2002.

\footnotetext{
Ahold (2003)

Tercer grupo mundial de distribución alimentaría, con sede en los Países Bajos.

- En el 2002 y el 2003 se acrecentaron las dudas sobre la fiabilidad de los estados financieros de Ahold.

- En febrero del 2003, Ahold admitió que había exagerado los beneficios correspondientes al 2001 y al 2002 en al menos 463 millones de euros, lo que provocó una caída inmediata del 63\% del precio de las acciones.

- Entre finales del 2001 y febrero del 2003, Ahold perdió el 90\% de su valor de mercado.
} 


\section{Referencias Bibliográficas}

Avilia Lammertyn, R. (1997). RR.PP, estrategias y tácticas. Buenos Aires: Imagen.

Bolsa de comercio de la ciudad de Buenos Aires (2006). Disponible en: www.bcba.sba.com.ar Bull Marker Brokers (s/f). Productos. Disponible en: www.bullmarketbrokers.com/generico.php ?fuente= productos.htm

Burson Masteller (2005). Corporate \& financial communications. Disponible en: www.bm.com Clip, J. (Dir.) (2004). Guía del FMI. Washingon: Fondo Monetario Internacional.

Cutlip, S y Center, A. (2001) Relaciones Públicas eficaces. Buenos Aires: Gestión 2000.

¿Qué es la bolsa? (julio 2006) El accionista. Disponible en: www.elaccionista.com.ar

Grunig, J. (2003). Dirección de Relaciones Públicas. Barcelona: Gestión 2000.

Fernández Escalante, F. (1999). Ciencia de la información y relaciones públicas. Comunicaciones, teoría de la opinión pública. Buenos Aires: Macchi.

Fleishman-Hillard (2005) Communication value. Disponible en: www.fleismanhillard.com

Forbes financial glossary (2005). Securities and Exchange Commission. Disponible en: www. forbes.com/tools/glossary/glossary.jhtml?letter=s

Grupo del Banco Mundial (s/f). Quiénes somos (sobre nuestra institución). Disponible en: www.web.worldbank.org/WBSITE/EXTERNAL/BANCOMUNDIAL/QUIENESSOMOS/0, menuPK:64058517 pagePK:64057857 piPK:64057865 theSitePK:263702,00.html

Grupo del Banco Mundial (s/f). Quiénes somos - Bancos multilaterales de desarrollo. Disponible en: www.web.worldbank.org/WBSITE/EXTERNAL/BANCOMUNDIAL/QUIENESSOM OS/0,,contentMDK:20193809 pagePK:64057863 piPK:242674 theSitePK:263702,00.html

INTA (s/f). Instrumentos financieros. Disponible en: http://www.inta.gov.ar/extension/finan/ tool/fondos.htm

Kastica, E. (2001) Desorganización creativa. Buenos Aires: Ediciones Macchi.

Lesly, P. (1998). Lesly's handbook of public relations and communications. New York: Mc Graw Hill.

Locante, G. (2004) Obstáculos y palancas para la capitalización y expansión de la pequeña y mediana empresa. Disponible en: www.eumed.net/libros/2006c/202/2e.htm

Fleisman-Hillard (2005) - communication value - Disponible en: www.fleismanhillard.com

Marston, J. (1990). Relaciones Públicas Modernas. México: McGraw Hill.

Marcus, B. y Lee, W. (1998). New dimensions in investor relations. New York: Wiley \& Sons.

Newson, D., Turk, J. y Kruckeberg, D. (2006). This is PR: The Realities of Public Relations. Belmont, California: Wadsworth Publishing

¿Qué es la CNV? (s/f) Disponible en: www.cnv.gov.ar

Relaciones Públicas Financieras (24/10/08). Belgrano PR. Disponible en: www.elgranopr.blog spot.com/2008/10/relaciones-pblicas-financieras.html

Ryan, T. y Jacobs, C. (2005). Using investor relations to maximize equity valuation. New Jersey: John Wiley \& Sons.

Seitel, F. (2002). Teoría y práctica de las Relaciones Públicas. (8va. Edición). New Jersey: Pearson. Stengel, G. (2006). Honing your investor presentation. Disponible en: www.stengelsolutions.com Turk, J., Newsom, D. y Kruckeberg, D. (1999). This is PR: The Realities of Public Relations. (7a edition). New Jersey: Wadsworth Publishing.

Wilcox, D. (2006). Relaciones Públicas, tácticas y estrategias. (8va.Edición). Madrid: Pearson. 
Yasky, D. (2010). Relaciones Públicas Financieras. Investor Relations \& Financial Communications Reflexión Académica en Diseño y Comunicación. Año XI, No 14. Buenos Aires: Universidad de Palermo.

\begin{abstract}
Summary: The role of Public Relations in the management of financial communications has been outstanding through the last years. The requirements of a greater access to information, transparency and corporate government create today significant challenges for all those companies that are players in the stock market, as well as of companies without official quote. The art of communicate in these spheres, requires the specialization of the professionals to reach the public adapted with the use of the pertinent tools at the opportune moment, transmitting strategically the message to the community. For this, it is necessary to recognize the outstanding actors of this scope - like international financial agents, stock markets, analysts, mass media, banks, public institutions, parliament, employees- and the interchange that takes place between the company and its investors.
\end{abstract}

Key words: Corporate communications - corporate reputation - Dircom - external public - Financial Communications - financial community - financial public - institutional communication - internal public - Investor Relations - management communication - mass media - Public Relations - stock market.

Resumo: Nos últimos anos, destacou-se a função das comunicações financeiras nas Relações Públicas. Os requisitos de um maior acesso à informação, transparência e governo corporativo criam hoje desafios significativos para todas aquelas companhias que cotam em Bolsa, bem como de assinaturas sem cotação oficial. A arte de comunicar nestos âmbitos, requer a especialização dos profissionais para atingir o público adequando com o uso das ferramentas pertinentes no momento oportuno, transmitindo a mensagem à comunidade em forma estratégica. Para isto, há que reconhecer os atores marcantes desde âmbito -como mercado de valores, agentes financeiros internacionais, analistas, meios de comunicação, bancos, instituições estatais, o parlamento, os empregados- e o intercâmbio que se produz entre a empresa e suas inversionistas.

Parlavras chave: Comunicação Corporativa - Comunicação empresária - Comunicação Financeira - comunicadores - comunidade financeira - Dircom - meios de comunicação - mercado de valores - público externo - público financeiro - público interno - Relações com os inversionistas - Relaçõoes Financeiras - reputaçao corporativa.

${ }^{*}$ ) Licenciado en Comunicación Social y Relaciones Públicas (UNLZ). Postgraduado en Comunicación de las Organizaciones, Opinión pública y Medios de Comunicación (FLACSO) y reaprender a pensar (pensamiento complejo) (USAL). Doctorando en Ciencias de la Comunicación (USAL). [Ver CV completo en la página 141] 